\title{
Relationship between Mother's Attitudes, Maternal Treatment Styles and Communication Competence with Deaf Children's Self-Esteem in Iran High Schools for the Deaf
}

\author{
Effat Hamed Sardar ${ }^{1}$, Rusnani Abdul Kadir ${ }^{2}$, Rohani Bt Ahmad Tarmiz ${ }^{3} \&$ Maria Chong Bt Abdullah ${ }^{4}$ \\ ${ }^{1}$ Department of Educational Psychology, Faculty of Educational, Universiti Putra Malaysia, Serdang, Malaysia \\ ${ }^{2}$ Department of Counselor Education and Counseling Psychology, Faculty of Educational Studies, Universiti \\ Putra Malaysia, Serdang, Malaysia \\ ${ }^{3}$ Institute for Mathematical Research, Faculty of Educational Studies, Universiti Putra Malaysia, Serdang, \\ Malaysia \\ ${ }^{4}$ Department of Foundations of Education, Faculty of Educational Studies, Universiti Putra Malaysia, Serdang, \\ Malaysia \\ Correspondence: Effat Hamed Sardar, Department of Educational Psychology, Faculty of Educational, Universiti \\ Putra Malaysia, 43400 UPM, Serdang, Selangor, Malaysia. E-mail: hamedsardar.effat@gmail.com
}

Received: July 5, 2012 Accepted: August 1, 2012 Online Published: September 20, 2012

doi:10.5539/ass.v8n12p67

URL: http://dx.doi.org/10.5539/ass.v8n12p67

\begin{abstract}
This study examines the relationship between mothers' attitude, communication competence, maternal treatment styles and self-esteem among deaf children who are currently enrolled in deaf high schools in Iran. Previous studies among deaf children have explored into factors such as types of education, parents' role, deaf parents' impact, the severity of deafness, age of onset, deaf child's communication at home and kinds of hearing aid used (Crocker, 2008). Other variables such as family's attitude, communication competence, and parental treatment styles have not been systematically explored. It is also not clear which factor affect deaf children's self-esteem. This survey was conducted at four deaf high schools in Mashhad, Iran. The sample consisted of 200 deaf children (100 boys and 100 girls) and 200 hearing mothers. Four inventories were used in the study: (1) Rosenberg Self-Esteem Scale (to measure children's self-esteem), (2) Parental Attitudes towards Deafness Scale (to measure mother's attitude), (3) Parental Acceptance, Neglect and Rejection Questionnaire (to measure maternal treatment styles), and (4) Communication Competence Scale (to measure communication competence). The children answered three questionnaires: Rosenberg Self-Esteem Scale, Parental Acceptance, Neglect and Rejection Questionnaire and Communication Competence Scale; while the mothers responded to Parental Attitudes towards Deafness Scale and Communication Competence Scale. In addition, the researcher conducted in-depth interviews with four deaf children and their mothers.

The results showed relationships between the mothers' attitude and deaf children self-esteem, communication competence and self-esteem in deaf children, and mothers' treatment styles and deaf children's self-esteem. It was found that in both groups (boys and girls), level of self-esteem was higher for deaf children who were from high income family, whose father and mother had higher education. No significant difference was found between genders in deaf children self-esteem. Finally mothers' attitude, communication competence, and their treatment styles were found to be predictive of self-esteem among deaf children.

Understanding the source of deaf children's self-esteem is important for it is the first step in developing self-esteem in deaf children. Helping professionals such as counselors and teachers should involve family members through counseling and coaching on how to manage their deaf children. The counselors can help hearing parents navigate through their feelings and reactions by acknowledging their feelings of disbelief, grief, guilt, and anger when there is a deaf child in the family.
\end{abstract}

Keywords: deaf children, self-esteem, mothers' attitude, treatment styles and communication competence

\section{Background}

Deafness crucially affects one's social-emotional development. Those who lack self-esteem usually feel 
desperate and this results in a certain attitude towards others. Deafness as a hidden disability cannot be observed as directly as other disabilities, and since society, to a great extent, relies on language, it is no wonder that many researchers have come to the conclusion that those suffering from impaired hearing have characteristics which differentiate them from hearing people (McGrath \&Grant 1993). A few researches have been done on different variables which affect children's self-esteem, such as the types of relationship at home, the age of onset, the severity of deafness, type of hearing-aid, and age of using hearing-aid (Jambor\& Elliott, 2005).

Other studies show that deaf students who attend normal schools with hearing students learn how to interact with hearing people and these students usually have higher self-esteem in comparison with those at special schools (Kluwin, 1999; Luckner, 1999). Other variables, such as the age of the onset of deafness, which are acquired in adulthood, create problems that are different from the problems of those who were born deaf or who lost their hearing during their early childhood (Munoz-Baell\& Ruiz, 2000).

In general, deaf children are liable to weaker self-esteem when compared to their hearing peers (Marschark, 2007). A study showed that children with hearing disorders have lower self-esteem in comparison with hearing ones or even blind ones. Deaf children are secluded, shy and have problems making friends. These children's teacher agreed with these findings. In a similar study it was shown that hearing children enjoy staying with friends while deaf children prefer to play alone. These children believed that nobody pays attention to them in the family and their parents have lost hope (Erting, 2001).

Nonetheless, there are factors which positively or negatively influence their self-esteem. For instance, deaf children who communicate with their parents through sign language have higher self-esteem than those with parents insisting on the use of oral communication (Foster, 1998). Another study showed the way that family members communicate can determine deaf children's self-esteem. Hence, it can be interpreted that when deaf children belong to a group, their self-esteem increases (LaSasso\& Metzger, 1998). This study only refers to the type of parent's communication. While correct communication with a deaf child can be effective in family relationships the lack of it causes low self-esteem.

Woolfe and Smith (2006), studied whether hearing parents or siblings are important in deaf children's self-esteem. A total of 45 deaf children with deaf parents and siblings, deaf parents with hearing siblings, and hearing parents with deaf siblings took part in this study. The result was higher self-esteem in those with hearing parents and the study did not show any important correlation among siblings, whether hearing or deaf. However, what was important was the families' connection in all the categories. Deaf children with deaf parents and siblings felt more intimately connected than those with hearing families (Woolfe\& Smith, 2006).

Another study was run to investigate the effect of communication patterns on a deaf child's self-esteem (Desselle, 1994). Deaf students at a special school for deaf children at the age of 13 to 19 were the subjects. There is no relationship between Parent's attitude and the use of sign language, but she was found a positive relationship between the student's self-esteem and reading level. The higher the reading levels of the deaf student, the higher were the self-esteem scores.

Jambor and Elliott (2005) studied the influence of self-esteem and the corresponding factors in deafness such as the severity of deafness and hearing-aid use in everyday life. They gathered data from students at the State University of Nortrich, California, and their findings showed direct correlation with the level of deafness. For example, those who had more severe deafness and got help from hearing aids had higher self-esteem than those who did not use hearing aids. It also proved that when accept deaf children are accepted in the deaf society, it has an important influence on them, although those suffering from severe deafness but who have two cultures (deaf-hearing) have better self-esteem.

Previous studies have investigated factors such as type of education, parents' role, deaf parents' impact, the severity of deafness, age of onset, deaf child's communication at home and the kinds of hearing aid used (Crocker, 2008). However, the focus of most of these studies has been on deaf parents' communication with their hearing children, while there has been little attention given to hearing parents' attitude towards deaf children and its correlation with the deaf child's self-esteem. This is both surprising and disappointing as $90 \%$ of deaf children have hearing parents (Lane, 1996). This present study therefore gives due attention to this gap in the research on how relationships between hearing mothers and deaf children can positively influence the self-esteem of the deaf children and subsequently lead to a reduction or elimination of behavioral problems.

Adolescence is an exciting time for young people and deaf students are no exception. The main editions that bring young customers to advising deaf focus to understand and accepting their hearing loss and the need to wear their hearing-aids, facing with abstract concepts to be different, including living in families hearing, taking care of maturation, miscommunication and peer pressure, directing anger, understanding and dealing with emotions, 
personal safety and issues of education, understanding consequences, reports and abuse and taking care gaps in general knowledge. So, the researchers have chosen deaf children in their adolescence period (13-20 years old).

\section{Methodology}

The quantitative methods were used to answer the research questions. Correlational research design can be considered as a suitable design for this study. The study also made use of a descriptive design. In other words, a descriptive study enables researchers to organize, summarize, and describe the observed data (Ary, Jocobs \& Razavieh, 2002).

Additionally, in an attempt to support the quantitative findings, four deaf children and their mothers were interviewed, because with interview, the researcher could have a clear understanding of the significant about mothers' attitude and deaf children's self-esteem. The population of this research is deaf children and their mothers in Mashhad city which they are studying in deaf high schools. The sampling method used in the present study was the simple random sampling method.

In this study, in the first stage, Self-esteem Rosenberg Scale, Acceptance, Rejection and Neglect Questionnaire, which were originally in English, were translated into Persian and the translation was confirmed by a university professor of psychology (Prof. KhadiviZand). Second, permission was obtained from Security Office of the Administration of Education for implementing the questionnaires at schools. Third, the main researcher was introduced to the schools for deaf students to conduct an actual study. Finally, the researcher selected 200 students along with their mothers from among 4 schools on a random sampling. The age group of these deaf students was included between 13 and 20 (In Iran, deaf children are allowed to finish high school up to age 22, due to their limitations and difficulties).

In addition, the main researcher due to her 20 years of experience in teaching and offering consultation to the deaf, as well as her mastery of Persian sign language and international standards, the researcher translated the questionnaire into the sign language herself, which took a long time.

The mothers were also invited to attend the meetings and answer the questions. The coefficient of Cronbach alpha was computed on 200 participants to indicate the reliability of instruments which implemented in pilot and actual research (see Table 1).

Table 1. Reliability coefficients cronbach's alpha

\begin{tabular}{lllll}
\hline Scale & ATDP & SEE & CCS & PANR \\
\hline Pilot Study & .71 & .57 & Deaf 74 & .70 \\
& & & Mothers 71 & \\
Actual study & .71 & .64 & $\begin{array}{l}\text { Deaf 75 } \\
\text { Mothers 63 }\end{array}$ & .78 \\
& & & & \\
\hline
\end{tabular}

ATDP: The attitude toward Deaf person's scale

SEE: Self-Esteem Scale

CCS: Communication Competence Scale

PANR: Parental Acceptance, Neglect, Rejection Questionnaire

\section{Instruments}

Four instruments were used for data collection, namely, the Attitude towards Deafness Person (the questionnaire was designed by the researcher herself), the Rosenberg Self-Esteem Scale (1995), Parental Acceptance, Neglect, Rejection Questionnaire (Elhageen, 2004), and Communication Competence Scale (Coromi\&Moradi, 2008). In addition, the demographic data which were asked from the respondents (deaf children) are: the age, the degree of deafness, the number of siblings, the number of siblings who have hearing problems, the numbers of respondent with or without hearing-aids used by the respondent, parents education, parents occupation and family income .

\section{Results and Discussion}

According to the results (see Table 2), there is a significant correlation between mothers' overall attitude and the children's self-esteem $(\mathrm{r}=-0.20, \mathrm{p}<0.05)$. 
Table 2. Correlation between components of mothers' attitude and deaf children's self-esteem

\begin{tabular}{lccc}
\hline Components of mothers' attitude & $\mathbf{N}$ & $\mathbf{r}$ & $\mathbf{p}$ \\
\hline Attitude & 200 & $-0.20^{* *}$ & 0.006 \\
Mothers' acceptance attitude towards deafness(AD) & 200 & $0.22^{* *}$ & 0.002 \\
Mothers' rejection attitude towards deafness(RD) & 200 & $-0.36^{* * *}$ & 0.000 \\
Mothers' attitude towards sign language(SL) & 200 & -0.10 & 0.15 \\
Mothers' attitude towards hearing-aid(HL) & 200 & $-0.20^{* *}$ & .005 \\
Mothers' attitude towards toward the learning(LP) & 200 & $0.21^{* *}$ & 0.002 \\
\hline
\end{tabular}

$* * \mathrm{P}<.01, * * * \mathrm{P}<.001$

Some researchers support this variable. Meadow-Orlands (1990) found that the positive thinking and attitudes of the family are critical to the growth and development of their child's self-esteem; families who approach deaf children's issues related to hearing loss in a positive way will then positively impact their children's self-esteem. However, in other studies, the relationship between the deaf child's self-esteem and their mothers' attitude about them has not yet been clearly discussed. What have been discussed were just overall positive and negative attitude about the issue. In this paper, however, five different categories were studied, namely, acceptance of deafness, rejection of deafness, mother's attitude towards use of hearing-aid, the mother's attitude about sign language and the mother's attitude about her deaf child's toward the deaf learning process.

In addition, Based on the Pearson correlation coefficients (See Table 3), there is significant positive and small relationship between self-esteem and communication competence of deaf children and their mothers $(\mathrm{r}=0.26$, $\mathrm{p}<0.05$ Based on the Pearson correlation coefficients which were revealed in Table 3 there is significant positive and small relationship between mothers' communication competence and deaf children's self-esteem $(\mathrm{r}=0.32$, $\mathrm{p}<0.05$ ). Some researchers can support the findings of current study. Mulcahy (1998) Factors potentially negative studies done in the esteem of deaf children. These were the low addresses communicative parents, low maternal report, the lack of confidence from the inequality and negative view towards deaf people. Social isolation and lack of cultural identity also influenced self-esteem of deaf children as confirmed by other studies. According to the Welfare authority of Iran, sign language is the best means of communication for the deaf. However, the organization of special education focuses primarily on an oral approach (Behmanesh, 2003). As a result, many parents are confused and they may fear that their children would be in sign language, even if Bat-Chava (1993) showed that deaf parents, who use sign language, have children with better self-esteem. These results may help to current research on deaf children's self-esteem and skills in sign language and mothers' communication competence.

Table 3. Correlation between self-esteem and communication competence in deaf children and their mothers

\begin{tabular}{llll}
\hline Deaf children's communication competence & $\mathbf{n}$ & $\mathbf{r}$ & $\mathbf{P}$ \\
\hline Deaf children's communication competence & 200 & $0.26^{* *}$ & 0.000 \\
\hline${ }^{* *} \mathrm{P}<.01$ & & & \\
\hline Mothers' communication competence & $\mathbf{n}$ & $\mathbf{r}$ & $\mathbf{p}$ \\
\hline Mothers' communication competence & 200 & $0.32^{* *}$ & 0.000 \\
\hline${ }^{* *} \mathrm{P}<.01$ & &
\end{tabular}

Also, based on Table 4 there is significant positive and small relationship between there is small and positive significant relationship between deaf children's self-esteem and children' perception of their mothers' treatment styles $(r=0.30, p<0.05)$. The results of existing studies on the relationship and mothers' treatment styles with children confirm that the first diagnosis is important in behavioral intervention programs to treat disorders of behavior. In other words, the perception of deaf children from their parents' treatment styles, especially the behavior of their mothers, is critical in reducing or increasing their self-esteem (Schilling and DeJesus, 1993).Almost no research has been conducted on the maternal treatment styles and deaf children's self-esteem.

Table 4. Correlation between deaf children's perception of their mothers' treatment styles and deaf children's self-esteem

\begin{tabular}{lccc}
\hline Maternal treatment styles & $\mathbf{n}$ & $\mathbf{r}$ & $\mathbf{p}$ \\
\hline Deaf children's perception of their mothers' treatment styles & 200 & $0.30^{* *}$ & 0.003 \\
\hline
\end{tabular}


For investigating the difference between boys' deaf children's self-esteem and girls' deaf children's self-esteem, independents two samples T-test was used. The results in Table 5 indicate there is no statistically significant difference between boys and girls deaf children in terms of their self-esteem [ $\mathrm{t}(198)=.39$. $\mathrm{p}>0.05)$.

Table 5. T-test, difference between genders of deaf children on their self-esteem

\begin{tabular}{llllllllll}
\hline & The gender & $\mathrm{n}$ & mean & Std. deviation & Std. Error mean & $\mathrm{t}$ & $\mathrm{df}$ & $\mathrm{Si}$ & $\mathrm{ES}$ \\
\hline Self-Esteem & Female & 103 & 2.9563 & .27104 & .02671 & .39 & 198 & .69 & 0.09 \\
& Male & 97 & 2.9711 & .26416 & .02682 & & & &
\end{tabular}

The relationship between difference in gender and self-esteem in deaf children has not been studied in depth in Iran although, based on western findings, it has been found the gender of the mentally disorders child may also influence the parents' acceptance of their child and level of stress. Mothers of disabled daughters report more stress than mothers of disabled sons. This may be related to the fact that mothers are more concerned about their daughter's appearance, menstrual needs, and sexual development (Lundgren \&Rudawsky, 1998).

According to results of Table 6, the self-esteem of deaf children of families who their income level is less than $400 \$$ is higher than other families' children self-esteem. In addition, there is significant difference among families income levels on their deaf child's self-esteem [F $(196,4)=.3 .01, \mathrm{p}<0.05]$.

Table 6. ANOVA analysis based on family's income

\begin{tabular}{lllllllll}
\hline Test & $\mathrm{N}$ & mean & S.D & min & Max & F & df & Sig \\
\hline$<400 \$$ & 12 & 3.01 & .29 & 2.50 & 3.60 & & & \\
$400-600$ & 111 & 2.94 & .24 & 2.30 & 3.40 & & & \\
$600-800$ & 62 & 2.92 & .25 & 2.40 & 3.50 & 3.01 & 196 & .01 \\
$800-1000$ & 9 & 3.01 & .25 & 2.70 & 3.40 & & & \\
$>1000$ & 2 & 2.50 & .23 & 2.50 & 2.50 & & & \\
\hline
\end{tabular}

Standard Multiple Regression was used to determine which of the independent variables (mothers' attitude, mothers' communication competence, children's communication competence and children's perception of their mothers' treatment styles) included in the model contributed to the prediction of the dependent variable (deaf children's self-esteem). The results in Table 7 indicated that beta value of the mothers' communication competence is larger than other independent variables, therefore this variable makes the strongest unique contribution to explain the deaf children's self-esteem and then children's perception of their mothers' treatment styles, mothers' attitude, children's communication competence make the unique contribution to explain the children' self-esteem respectively.

Table 7. Multiple regression analysis

\begin{tabular}{llllll}
\hline Variable & $\mathrm{B}$ & Std. error & $\mathrm{B}$ & $\mathrm{T}$ & $\rho$ \\
\hline Constant & 20.11 & 5.52 & & 3.64 & .000 \\
Attitude & -.068 & .050 & -.159 & -2.29 & .022 \\
Children' Competence & .016 & .010 & .155 & 2.16 & .030 \\
Moms' Competence & .030 & .010 & .239 & 3.08 & .002 \\
Treatment Styles & .172 & .073 & .163 & 2.36 & .019 \\
$\mathrm{R}$ & .684 & & & & \\
$\mathrm{R}^{2}$ & .468 & & & & \\
$\mathrm{~F}$ & 8.3 & & & & \\
\hline
\end{tabular}

In addition the $\mathrm{p}$ values of all independent variables are less than 0.05 , thus mothers' attitude, mothers' communication competence, children's communication competence and children' perception of their mothers' treatment styles are making a significant unique contribution to the prediction of the deaf children's self-esteem. Moreover, based on R square, our model (which includes mothers' attitude, mothers' communication competence, children's communication competence and children' perception of their mothers' treatment styles) explains $46.8 \%$ of the variance in deaf children' self-esteem. The deafness or hearing impairment itself does not directly cause poor self-esteem, but the ability to communicate may be a contributing factor to self-esteem (Schlesinger 
\& Meadow, 1972). The mother-child dyad's ability to communicate effectively becomes more important as the child grows older because corresponding age-appropriate activities become increasingly dependent on language (Lederberg \& Mobley, 1990). Unfortunately, in hearing families, "the early development of the mother-child bond necessary for positive feelings of self is often impeded by the hearing-impaired child's ability to communicate" (Loeb \&Sarigiani, 1986). This impediment sets up a cycle in which the parents are frustrated because they cannot communicate with the child and the child internalizes this frustration (Schlesinger \& Meadow, 1972). Marschark (1993) noted that hearing impairment leads to psychological impairment, which leads to problem behavior.

In an attempt to support the quantitative findings, four deaf children and their mothers were interviewed, because with interview, the researcher could have a clear understanding of the significant about mothers' attitudes towards deafness.

In order to more deeply examine the feelings of deaf people about themselves and the concepts of self-esteem, the researcher chose four deaf children with an average hearing level and asked them to say what they feel about their disability. After they had drawn their drawings, they were asked to draw what they thought about the way they communicate with their mothers. The findings of interviews showed that while accepting the child as deaf and respecting his/her needs to sign, he/she will take a positive attitude toward himself/herself (See Table 8).

Table 8. Summary of the results of Interviews with deaf children

\begin{tabular}{ll}
\hline How do you feel about being deaf? & Interview \\
\hline I am able to do things as well as most other people. & Code 1 \\
I certainly feel useless at times. & Code 2 \\
I feel I do not have much to be proud of. & Code 3 \\
On the whole, I am satisfied with myself and my family. & Code 4 \\
\hline
\end{tabular}

\section{Recommendations for Future Research}

The current research shows how a variety of quantitative statistical analysis can be used together with interview data to complement each other. The findings and conclusions drawn from this study are constrained by the characteristics of these specific passages used in the present research and may not be generalizable to other reading passages and contexts of study.

Based on the results taken from interviews and quantitative methods of research, the following instances are recommended to enhance the deaf children's self-esteem:

a) Opening simultaneous sign language classes for both deaf children and their mothers (especially those who are weak in communicating).

b) Having group consultation sessions for mothers or group therapy. Not only will these sessions bring them closer together, they will also able to hear about others' experiences, and this can finally change their attitudes about disability.

c) Incorporating specific programs for deaf people on television which will inspire self-motivation in them. Producing TV programs that deaf people can understand will cause them to feel that they are also part of he/she is here in this world and there is no difference between them and others (Ghahraman, 1998).

d) Paying attention to deaf people and their families' mental health by establishing specific centers for deaf people and asking them to participate in these classes to tell their problems to officials.

e) Having active consultants, even in hostels, which use different methods (encouragement, make-up programs) to help deaf children enhance their self-esteem.

f) Training parents to treat their deaf children appropriately by opening training workshops.

g) Establishing short-term Interim Service Courses for educational staff, especially the consultants, to familiarize themselves with the newest consulting techniques and using them to enhance the deaf children's self-esteem.

h) Encouraging more cooperation between the Exceptional Education Bureau and, the Welfare Office to achieve the goals which can finally result in a more consistent and cohesive communication for those abovementioned offices and also for deaf children and their parents.

i) Conducting recreational expeditions for families and their deaf children in order to bring serenity and more communication to those families. 
j) Organizing co-intellectual councils which consist of the people in charge of the Education Bureau, the Welfare Office and the representative parents to talk about the numerous problems of deaf children and their families.

The effect of painting therapy on enhancing communications is a subject for future research.

The relationship between authoritative parenting style and deaf children's self-esteem is a subject for future research. In another study, the sample of research could be selected from among the deaf children with single parents or the deaf children with deaf parents. In addition, mother's attitudes can include other components such as mothers' attitude towards the teachers of their deaf children.

\section{References}

Ary, D., Jacobs, L. C., \& Razavieh, A. (2002). Introduction to research in education. Belmont, CA: Wadsworth/Thomson Learning.

Bat-Chava, Y. (1993). Antecedents of self-esteem in deaf people: A meta-analytic review. Rehabilitation Psychology, 38, 221-234. http://dx.doi.org/10.1037/h0080303

Behmanesh, A. (2002). Deaf Way II Presentation on Iranian Deaf Culture. Reo Cities.

Berg, Steiner. (2003). Children's solutions work. Newark: Norton \& Co. Ltd.

Coromi, M., \& Moradi. A. (2008). Learning Disability Questionnaire. Iran: Shiraz University.

Crocker, J., \& Luhtanen, R. K. (2008). Level of self-esteem and contingencies of self-worth: Unique effects on academic, social, and financial problems in college students. Personality and Social Psychology Bulletin, 29, 701-712. http://dx.doi.org/10.1177/0146167203029006003

Deselle, D. (1994). Self-esteem, family climate, and communication patterns in relation to deafness. American Annals of the Deaf, 139, 322-328. http://dx.doi.org/10.1353/aad.2012.0295

Elhageen, M. (2004). Effect of Interaction between Parental Treatment Styles and Peer Relations in Classroom on the Feelings of Loneliness among Deaf Children in Egyptian Schools. Retrieved from http://www.wvberlin.de/data/inhalt/elhageen.htm

Erting, L. (2001). Book sharing the Deaf Way: An Ethnographic study in a Deaf Children. Dissertation Abstracts International, UMI no.3035993.

Foster, S. B. (1998). Communication experiences of deaf people: An ethnographic account. In I. Parasnis (Ed.), Cultural and language diversity and the deaf experience (pp. 117-135). New York: Cambridge University Press.

Ghahraman, R. (1998). The role of TV in living of disability people. Journal of Exceptional children, 4.

Jambor, E., \& Elliot, M. (2005). Self-esteem and Coping Strategies among Deaf Students. Journal of Deaf Studies and Deaf Education, 10, 63-81. http://dx.doi.org/10.1093/deafed/eni004

Kluwin, T. (1999). Co-teaching deaf and hearing students: Research on social integration. American Annals of the Deaf, 144, 339-344. http://dx.doi.org/10.1353/aad.2012.0337

Lane, H. (1996). A journey into the deaf world. San Diego: DawnSign Press.

LaSasso, C. J., \& Metzger, M. A. (1998). An alternate route for preparing deaf children for BiBi programs: The home language as L1 and cued speech for conveying traditionally spoken languages. Journal of Deaf Studies and Deaf Education, 3(4), 265-289. http://dx.doi.org/10.1093/oxfordjournals.deafed.a014356

Ledenberg, A. R., \& Mobley, C. (1990). The effect of hearing impairment on the quality of attachment and mother-toddler interaction. Child Development, 61, 1596-1640. http://dx.doi.org/10.2307/1130767

Loeb, R., \& Sarigiani, P. (1986). The impact of hearing impairment on self-perceptions of children. Volta Rev, 88(2), 89-100.

Luckner, J. (1999). An examination of two co-teaching class-rooms. American Annals of the Deaf, 144, $23-43$. http://dx.doi.org/10.1353/aad.2012.0180

Lundgren, D. C., \& Rudawsky, D. J. (1998). Female and male college students' responses to negative feedback from parents and peers. Plenum Pub Corp.

Marschark, M. (1993). Psychological development of deaf children. New York: OxfordUniversity Press.

Marschark, M. (2007). Raising and educating a deaf child: A comprehensive guide to the choices, controversies, and decisions faced by parents and educators (2nd ed.). New York: Oxford University Press. 
McGrath, M., \& Grant, G. (1993). The Life-cycle and Support Networks of Families with a Person with a $\begin{array}{lllll}\text { Learning Difficulty. Disability, Handicap and Society, } 8, & \text { 25-42. }\end{array}$ http://dx.doi.org/10.1080/02674649366780021

Meadow-Orlans, K. P. (1990). The impact of a child's hearing loss on the family.

Meadow-Orlans, K. P., \& Steinberg, A. G. (1993). Effects of infant hearing loss and maternal support on mother-infant interaction. Journal of Applied Developmental Psychology, 14, 407-426. http://dx.doi.org/10.1016/0193-3973(93)90017-P

Mulcahy, R. T. (1998). Cognitive self-appraisal of depression and self-concept: Measurement alternatives for evaluating affective states. Unpublished doctoral dissertation, Gallaudet University.

Munoz-Baell, I. M., \& Ruiz, M. T. (2000). Empowering the deaf: Let the deaf be deaf. Journal of Epidemiology and Community Health, 54, 40-44. http://dx.doi.org/10.1136/jech.54.1.40

Rosenberg, M. (1995). Global self-esteem and specific self-esteem: Different concepts, different outcomes. American Sociological Review, 60, 141-156. http://dx.doi.org/10.2307/2096350

Schilling, L. S., \& DeJesus, E. (1993). Developmental issues in deaf children. Journal of Pediatric Health Care, 7, 161-166. http://dx.doi.org/10.1016/0891-5245(93)90039-K

Schlesinger, H. S., \& Meadow, K. P. (1972). The deaf population of the United States. Silver Spring, MD: National Association of the Deaf.

Woolfe. T., \& Smith.P. K. (2006). The self-esteem and cohesion to family members of deaf children in relation to the hearing status of their parents and Siblings. Deafness \& Education International Online Journal, 3(2), $80-96$.

\section{Appendix}

Summary of the results of interviews with mothers

\begin{tabular}{ll}
\hline Interview & What is your attitude towards your deaf children? \\
\hline Code 1 & $\begin{array}{l}\text { At first I was shocked but my husband's sympathy and visiting rehabilitation centres helped me to } \\
\text { accept my child's being deaf. }\end{array}$ \\
Code 2 & $\begin{array}{l}\text { I am upset because my son can't hear. The rehabilitative facilities are limited in schools. The } \\
\text { number of students is too much while the facilities are too less. }\end{array}$ \\
Code 3 & $\begin{array}{l}\text { I am upset because my son can't hear. The rehabilitative facilities are limited in schools. The } \\
\text { number of students is too much while the facilities are too less. }\end{array}$ \\
Code 4 & $\begin{array}{l}\text { I have accepted the reality of deafness, but I feel that his deafness causes other family members to } \\
\text { be nervy. When we are watching TV programmes and my son asks others to explain it to him, they } \\
\text { become nervy because they don't have time to do so. }\end{array}$ \\
\hline
\end{tabular}

